\title{
Comparison Shopping Engines
}

\section{State of the Art, Exposure of Shortcomings and Discussion of New Innovations}

\author{
Ghizlane LAGHMARI ${ }^{1}$, Sanae KHALI ISSA ${ }^{2}$, M'hamed AIT KBIR ${ }^{3}$ \\ Laboratory of Informatics, Systems and Telecommunication (LIST), \\ Computer Science Department, Faculty of Science and Technology, Abdelmalek Essaadi University \\ Tangier, Morocco
}

\begin{abstract}
Since the stimulation of both feelings of need and temptation have become excessive with the spread of internet advertising, the e-consumer have begun to feel increasingly lost and overwhelmed by offers in a purchasing cycle whose process is mostly unstructured, unguided, and unassisted or - in other words - non user-friendly. As a result, he displays a confused and suspicious attitude and desperately turns to the comparison shopping engines (CSEs) to save time and identify the best matching offer for his search request. Thus, the article in question serves as an investigation of the comparison shopping engines to know if they are up to the task of satisfying the needs of the e-consumer. This study adopts an exploratory approach about the history of online shopping engines, their operating modes, categories, and business plans as well as how they are perceived, used and evaluated. Then, a detailed identification of the various shortcomings that CSEs manifest on the side of both e-consumers and e-merchants was presented in order to eventually discuss the numerous innovations and scientific research which have been developed on the subject.
\end{abstract}

Keywords-Price comparators; shopbots; e-consumer; online consumption; shopping engines

\section{INTRODUCTION}

Consumers around the world are witnessing a rapid change with the increased digitization and globalization of markets [1]. Moreover, the emergence of new ways of communicating, electronic banking, e-purchasing and e-learning have changed most of economic interactions in the world [2]. This change, which increases both the number of choices and opportunities, intensifies the pressure on the consumer and promotes confusion in the world of digital consumption [3]. Today's online consumer is increasingly overwhelmed by offers that he is unable to evaluate [4].

In order to control damages, digital institutions with strong commercial influence have embarked on a search for an intelligent solution that will maintain the Internet user's uninterrupted contact with their products and promote their consumption. This solution should also reduce his confusion and feeling of overload by presenting him with the most suitable offer for his search. Thus, the comparison shopping engines (CSEs) appeared with the aim of assisting the consumer in his consumption process by easing his confusion through increasing the transparency and exhaustiveness of the service [5][6]. However, are they up to the expectations of the consumer? Do they meet his needs in respect of his believes and his the privacy of his virtual identity?
This article answers these questions and discusses their turnings according to the following structure: In the first section the article presents the concept of Comparison Shopping Engines (CSEs) and their different categories, the history of their creation, their Business Plan, their system of functioning as well as how to evaluate the relationship between a CSE and the online consumer. The second part was devoted to the presentation of an investigation the different disadvantages and limits of the current CSEs, either from the side of the consumer or that of the e-merchant. On the other hand, the third part was devoted to the elaboration of a discussion around the different scientific articles and innovations that have addressed this topic, whether with the vision of criticizing, improving or innovating in the field of comparison shopping agents.

\section{COMPARISON SHOPPING ENGINES}

\section{A. Definition and Nomenclature}

A comparison shopping engine (CSE) is an online service centralized in a website which, based on a request for a product or a service (bag, computer, washing machine, trip, hotel reservation...), will establish a list identifying certain factors of the product/service sold by several e-commerce platforms [7][8]. For each specific request, a list of offers collected from the e-commerce platforms surveyed is presented in price order according to the user's (decreasing or increasing) wishes[9]. In addition to the price, this list sometimes includes other specifications such as delivery details, payment methods and some technical information [10].

Comparison shopping engines (CSEs) have several nomenclatures, including:

- Shopbots, which is a term for the software agent on the main server of the comparison service [11].

- Price bots or "price comparison engines", which goes to the extent of allowing consumers to find the best price for a given product [12].

Or other designations such as: Price comparison websites, comparison shopping websites, e-commerce recommendation engines, etc.

\section{B. History}

The first shopping engines appeared in the mid-1990s [13][6]. BargainFinder was the first widely recognized product comparator, it was developed by a team led by Bruce Krulwich who worked for Andersen Consulting (now Accenture) in 1995 
[7]. In 1995, BargainFinder was followed by the first price comparator, called Jango, created by the start-up Netbot, which was acquired by the Excite portal at the end of the same year [13]. Other start-ups were also interested in comparison shopping engines technology such as Jungle, which was acquired by Amazon.com, pricewatch.com, killerapp.com and NexTag which was nominated by Times Magazine World as one of the top 50 websites in 2008 [14]. Just after the economic crisis, like all global markets, comparison shopping engines found their way into emerging markets. With CompareXpress in Singapore in 2010, Baoxian (China), Jirnexu (Malaysia) and AskHanuman (Thailand) [10] whish, in 2013, increased its activity with solid investments in Big Data-oriented platforms, given the massive increase in data to be processed. Other price comparison websites such as FindTheBest, Priceza, Malaysia, Iprice and Save 22 have followed in the footsteps of AskHanuman in including this strategy.

\section{Categories of Comparison Shopping Engines}

The current CSEs are divided into multiple categories:

- General comparison sites: they are the most common on the web, generating a very wide spectrum of product categories (household appliances, entertainment, food, etc.) and services (insurance, travel, credit, etc.) [15].

- Specific comparison sites: these types of sites have come to specialize in particular areas to limit the plethora of online offers and be more exhaustive in their service. Example: travel comparators (Easyvoyages, Opodo, e-bookers,...), insurance comparators (Assurland, Kelassur, Le Lynx,...), etc. [15].

- Alternative Comparators: these are sites that allow you to find and rank a wide range of offers according to alternative criteria, such as geographical position or consumer opinions (Vozavi) [16].

- Hybrid comparators: these are sites that adopt a generalist approach while offering paid internal referencing services for merchants (Twenga) [17].

\section{Business Plans of Comparison Shopping Engines}

Regardless of the nature of the CSEs, they all generate their income based on one or more of these business models:

- Cost Per Action (CPA): This model is based on partnership agreements between CSEs and e-merchant websites to which they refer consumers. The referencing and ranking of e-merchant websites in a comparator are often managed in such a way that the latter yields a commission on each redirection or sale conducted through the comparison engine [15].

- The pay-per-click (PPC) or cost per click (CPC) system: each click by an Internet user towards an e-merchant website from a CSE provides the latter with an income of around 5 to 70 euro cents. CSEs generally propose to cap the monthly budget of their e-merchants. Thus, when the sum of clicks reaches the determined limit, the e-merchant's products no longer appear until the beginning of the following month [15].
- Fixed commercial agreements with associated emerchant websites, which may take multiple forms such as "entry fees".

- Promotions and advertisements: Many comparators show ongoing promotions on displayed products or other products related to the research field [18].

The majority of CSEs generate their revenues on the basis of all the above mentioned. However, there is no doubt that there are those who, out of integrity, are solely satisfied with the revenues from the advertisements displayed on their pages [15].

\section{E. How Price Comparators Work}

The basic operating process of a comparison shopping engine includes the collection, storage, comparison and presentation of data. However, it is the data collection methods that distinguish most of the current CSEs. These can be roughly divided into four categories:

- Data Feeding: this method consists of the merchant website manager entering the initial information of the products and the catalog of the offers directly on the comparison website [13]. This method of supplying data essentially consists of allowing or encouraging online merchants to provide the data associated with the products they offer (the price or other specifications such as shipping costs, stock levels, discounts, etc.) in the specific data format defined by the CSEs. While allowing them to update their information as they see fit [13].

However, with the increasing number of comparison shopping websites and the excessive number of products to download, e-merchants feel bombarded by a huge amount of work, hence the need to use a specialized data flow management service has emerged. These needs have led to the creation of CSE data power management services such as SingleFeed [19] and FeedPerfect.

- Affiliate feeds: this technique consists of retrieving and directly filling in offer catalogs by connecting to emerchant APIs [17][21]. This is achieved through downloading flows from their respective affiliate accounts to fill the catalog, display and update prices and information in real time. This method is considered the fastest but perhaps less accurate and, above all, less informative. Since only basic information is available via feeds such as title, URL, etc. [21].

- Data Wrapping: is a data recovery technique that can be performed automatically or manually to identify information contained in a web page and then transform it into a consistent format for further processing [13].

It is a method of extracting the content from a particular information source and translating it into a relational form. Despite its slowness, due to the impossibility of exploring websites beyond a certain rate, it remains very rich and accurate. However, there are limitations that can be seen in the fact that many websites tend to set up Anti-Wrapping mechanisms to avoid being bombarded with too many requests [15]. 
- Data recovery from meta-engines: this technique is used by a new generation of price comparators which no longer base their searches on a selection of e-commerce websites but on the purchase comparators themselves by gathering information through queries from several price comparators and search engines [15].

Although data collection methods can be quite diverse, comparison methods to date remain largely based on the bid price factor, although the formula for exposing results may vary from one comparator to another depending on the display filters available, such as [15]:

- The relevance of the product to the user's request.

- The response time of online shops.

- The amount of information provided on the product.

- The number of sales made.

- Popularity (number of clicks by Internet users).

- The ranking filters chosen by Internet users [15].

\section{F. The Relationship between the Internet user and the} Comparison Shopping Engines (CSEs)

1) The consumer decision-making process and the use of the CSE: If we consider the classic model presented by Calin Gurau [13] on the decision-making process that a consumer maintains with a CSE, the latter uses the comparison shopping engine in three main cases, as illustrated in Fig. 1.

Another way of looking at things was presented by Guttman, Moukas and Maes in 1998 [22] that presents a somewhat different model from the previous one, which explains the six-step consumer-CSE contact process:

- Identification of needs;

- Product brokerage;

- Brokerage in e-merchants;

- Negotiation;

- Purchase and delivery;

- Service and evaluation [22].

Also, another vision of approaching the consumer decisionmaking process and the use of CSE has been studied by Rowley (200b) as shown in Fig. 2 [13]. However, although these processes are quite sequential and logical, they do not provide any indication of consumer attitudes/behavior during the research process [13] or of their satisfaction with the service provided.

2) The characteristics that determine a consumer's satisfaction with an online service: The evaluation of the elements influencing the feeling of satisfaction with the use of an online service was perceived in several ways. According to the SERVQUAL model, presented by Parasuraman, Zeithaml and Berry in 1988 [23], the quality of an online service can be determined according to the following characteristics: tangible assets, reliability, responsiveness, competence, courtesy, communication, credibility, security, accessibility, and customer understanding [23]. Then, using factorial analysis, these dimensions were reduced to five characteristics: tangible assets, reliability, responsiveness, assurance and empathy [23].

However, given the speed of digital transformations and the enormous growth of online services, these characteristics have required significant adaptation. Zeithaml, Parasuraman, and Malhotra, therefore, identified in 2002 an improved set of the above-mentioned characteristics [24]: reliability, responsibility, accessibility, flexibility, ease of navigation, efficiency, assurance/trust, security, price-knowledge, site aesthetics and personalization, developing on their basis an e-SERVQUAL model [24].

However, these features may apply primarily to retail websites, which are more or less more complex than current price comparators.

3) The characteristics determining a consumer's satisfaction with the quality of a CSE: A study also conducted by Calin Gurau [13], aimed at defining the determining characteristics of the quality of a CSE for a consumer. The study was based on a set of interviews conducted with 121 respondents who indicated the characteristics that define the quality of a CSE for them [13].

At first, $81 \%$ of respondents considered the ability of the CSE to find a lower price offer to be a very important criterion [13]. Second, $80.2 \%$ of respondents highlighted ease of interaction as an important aspect of their contact with a CSE [13], knowing that this criterion was presented to them under several characteristics including reliability, functionality, ease of navigation, clarity of the various information/indications and the available tools (search, selection in a list, order of results according to various headings ...) of the comparison website [13]. In third place, the accuracy of the comparator in finding the right desired offer is considered important by $76.8 \%$ of respondents [13]. Followed by $70.2 \%$ of respondents who say that the desire to have additional information about the offer and/or the supplier is important to them [13]. Finally, 58.7\% of respondents like CSEs which, in addition to online offers, also provide access to the ratings, comments, and evaluations provided by former consumers [13].

In addition, Calin Gurau [13] interprets these results in a different way when she considers the existence of a good dependency relationship between these characteristics. Thus it states that as the price level becomes average and low, the need for additional information becomes less important. On a side note, the proportion of people who indicated the importance of ease of interaction remains quite indifferent to price [13]. 


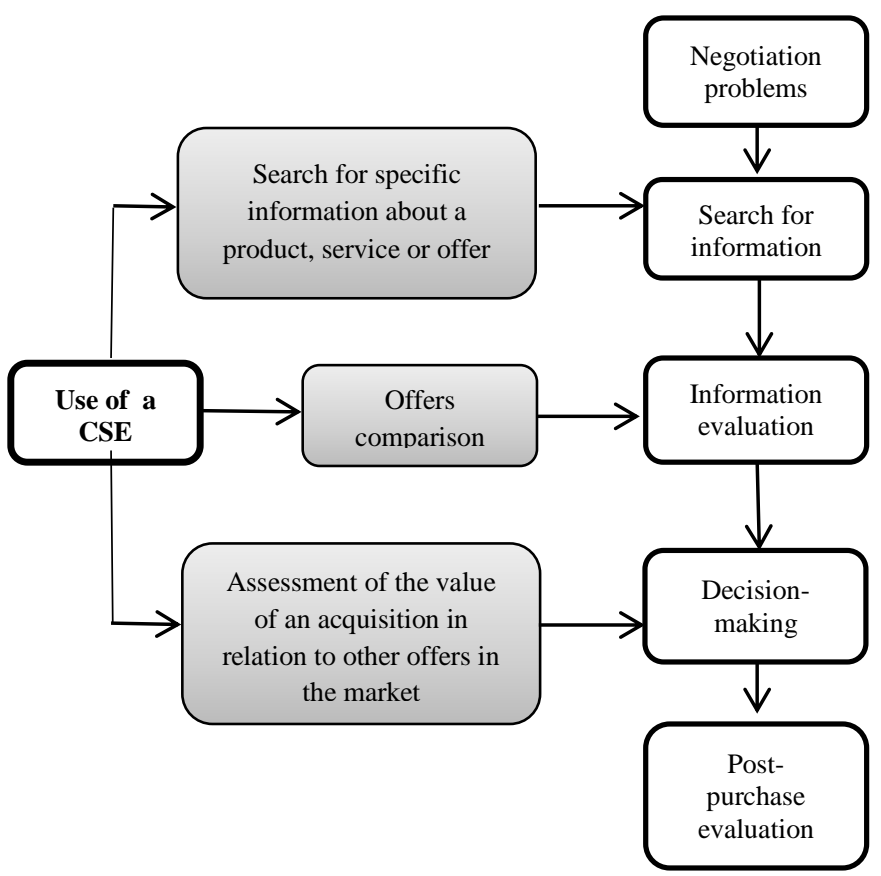

Fig. 1. The Consumer Decision-Making Process and the use of the CSE [13].

Consumer: Choosing a comparison shopping engine

Consumer: Specifying product search parameters

$\downarrow$

CSEs : Displaying search results

$\downarrow$

Consumer: Limiting the search by selection filters if necessary

$\downarrow$

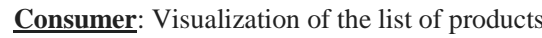

$\downarrow$

Consumer: Selecting the product for further examination

$\downarrow$

CSEs : Visualization the details of the selected products

$\downarrow$

Consumer: Choice of potential product

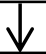

Consumer: Ordering the product
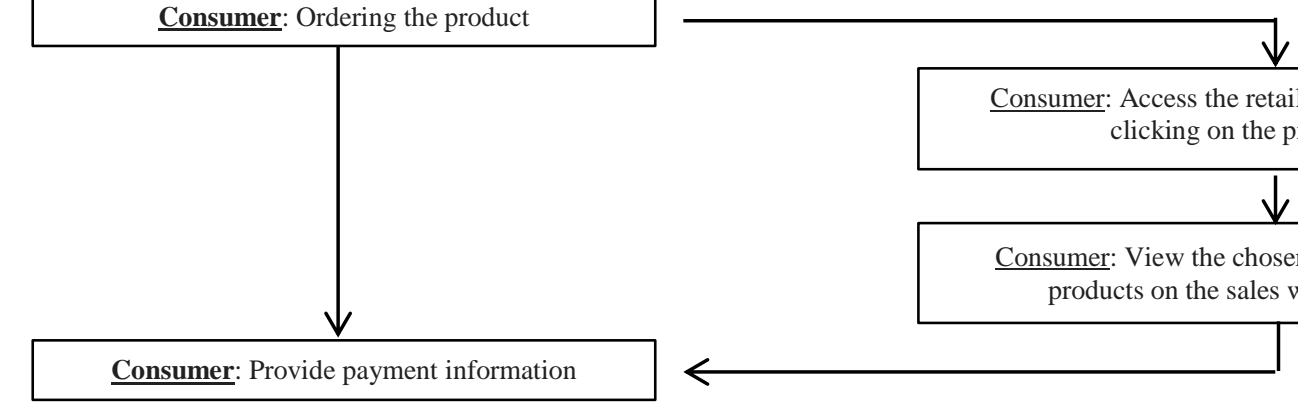

Consumer: Access the retail websites in detail by clicking on the product link

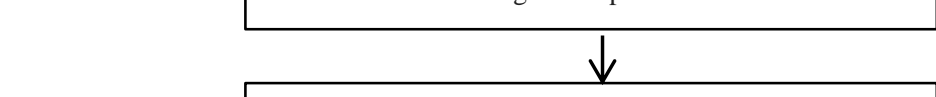

Consumer: View the chosen product and similar products on the sales websites in detail

Fig. 2. The Process of Searching and Acquiring a Product using CSEs [13]. 


\section{SHORTCOMINGS OF THE COMPARISON SHOPPING ENGINES}

Despite the important change that the comparison shopping engines have made, whether for the benefit of e-merchant websites or for the benefit of e-consumers, and although they have significantly improved in recent years, they still present some limits that must not be omitted in order to adapt to an econsumer increasingly informed, curious and driven towards the notion of a good deal.

\section{A. Shortcomings Affecting the E-consumer}

The relevance of the price comparators and their benefits for the e-consumer are undeniable. Based on the valuation of the least expensive price, CSEs create competition between emerchants which reduces the price to the benefit of the econsumer [25] [26]. Moreover, it reduces the time the consumer spends searching for a product [11] [27] [28]. However, all these advantages remain insufficient considering that all the factors induced by the new era of marketing and digital transformations encourage the CSEs to review their approach [29]. Among the CSEs shortcomings considered significant are those presented in Fig. 3.

\section{1) Insufficient functionality and adaptability}

a) Inadaptability of results: This limitation is explained by the absence of the consideration of certain characteristics of the product desired by the consumer in the search and/or the comparison of offers; the thing that gives results that are not totally adapted to the need of the e-consumer. A customer already overwhelmed by all online offers and advertisements [3], or looking for particular criteria, finds himself unsatisfied and unable to decide, faced with a list of offers whose only criterion often valued during the comparison is: the price, especially since the variation in prices between e-merchants is mostly insignificant [11]. Thus, he feels obliged to go and do the work of comparing the other criteria himself in order to make a good decision.

b) Non-exhaustiveness of results: While the consumer uses a CSE to carry out on his behalf a general search of existing offers on the web for a product he wants, he finds himself presented with a small pre-prepared list following commercial arrangements between CSEs and e-merchants [30][28]. A study carried out by the DGCRF (General Directorate for Competition Policy, Consumer Affairs and Fraud Control) reveals that the majority of CSEs do not relay all the offers in a sector, but only those of partner merchant website. Thus, the informed consumer has the feeling that he is being manipulated by the omission of other offers that may be more interesting for him. This can damage completely the reputation of the comparator.

\section{2) Lack of transparency}

a) The omission of certain information by CSEs: The majority of price comparators choose to omit certain specifications while offering their price comparison, such as the price in VAT or the delivery price, which may be higher than the price of the product in some cases [13]. This completely distorts the relevance of the classification, causing it to lose the consumer's trust.

b) The non-ethical arrangements between the CSEs and the e-merchants: Most of the comparators base their offers' comparison on arrangements made with e-merchants[30]. Thus, in their ranking, some choices are more visible or better ranked than others, which can distort the e-consumer's judgment [30]. As a result, and following the complaint of certain consumers, who require comparison sites to provide impartial information [31], and the recommendations made by the DGCCRF (General Directorate for Competition Policy, Consumer Affairs and Fraud Control), a code of ethics for comparators was adopted on 11 June 2008, giving rise to the label "comparator charter" [31], whose signatories undertake to:

- Be more transparent about the prices displayed (including VAT, delivery costs) and the criteria that govern the classification of offers.

- Specify the non-exhaustiveness of the search results.

- Refresh the processed data at least every 24 or 18 hours [31].

3) The lack of consideration of consumer preferences in the evaluation of offers: Besides, the criteria attached to the offer (product/service specifications, the offer bonuses, price, etc.) or those specific to the consumer's profile (age, gender, etc.) that some CSEs take into consideration when collecting offers, there are other criteria that are as important to consider in the collection and evaluation of offers. These criteria are mainly based on preferences that deeply affect the health of the consumer and his consumption believes [32].

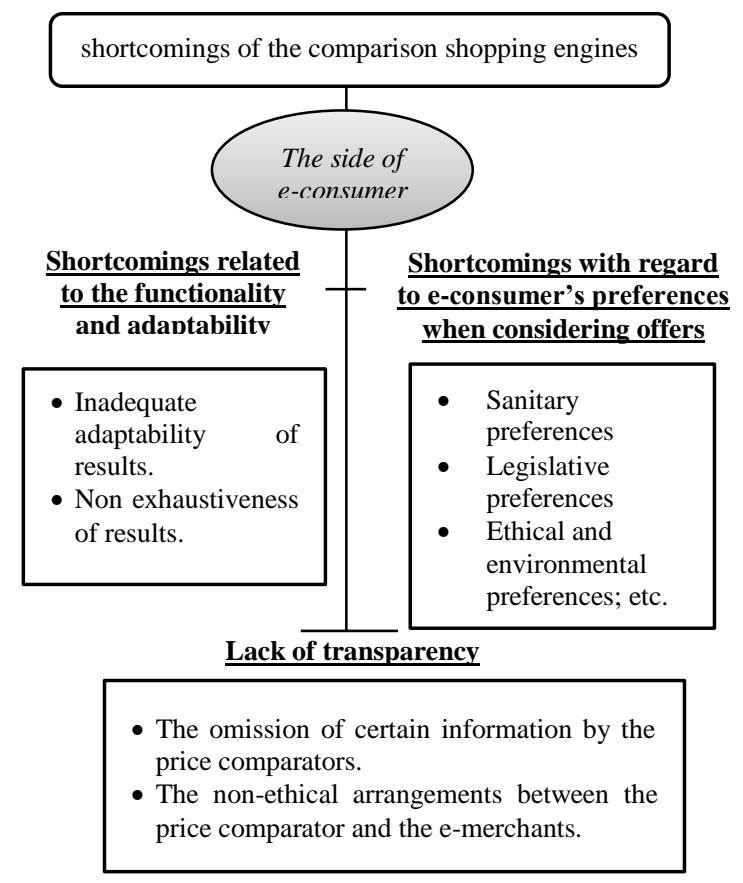

Fig. 3. Shortcomings of the Comparison Shopping Engines: the eConsumer's Side. 
a) Health preferences: Several products with strong allergenic substances or totally defective substances are put on sale on the online market (drugs, food supplements, food products, hygiene products, cosmetics, Ayurveda products, etc.) [33]. For instance, multiple allergies, intoxications and dangerous diseases are caused either by the allergenic substances in food products, the increasing complexity of the food chain, the emergence of biotechnologies and the emergence of new products with poorly controlled consequences either in their content (genetically modified organisms, use of dangerous dyestuffs: E102, E110, etc. [34], use of heavy metals [35]), or in their packaging (use of nanotechnologies in packaging to increase shelf life) [36]. Thus, the consideration of these factors, whether in the evaluation of the offer or in raising the awareness of the econsumer prior to purchasing the product in a transparent, efficient and understandable manner, remains essential, increases purchases [37] and creates a relationship of loyalty and trust [34].

In the cosmetic field some websites offers exclusively a service that considers the consumer's health preferences, such as INCI Beauty[38], QuelCosmetic [39], etc. However, it still has a limited existence on the web in general, endangering the health of many consumers who lack the knowledge or time to do all the necessary research by themselves.

b) Moral and legislative preferences: The lack of consideration of legislative standards and risks may manifest itself in the absence of rising the consumer's awareness or warning him of the laws of the country of destination, related to the consumption or order of a product especially those that are suspicious (contraband products [40], counterfeit products [41], stolen products, expired products, toxic products, etc.) and/or the authorized quantity of the latter. Because, this could cause several problems for the consumer, such as the loss of money in the confiscation of the product by customs, very high customs fees as well as penalties, and even jail time [42].

In line with current marketing trends focused on rising the customer's awareness, a consumer should be notified of the legal risks, customs measures and any other possible risks (diseases, allergies, etc.) for any product before ordering it, so that he can make a responsible decision.

c) Ethical and environmental preferences: The current consumer is becoming increasingly educated and involved in the manufacturing process of his products [43]; however, this is not well taken into account by CSEs. For example, in the case of customers who are sensitive to products tested on animals or manufactured in conditions (child labor, etc.) that do not respect employment rights etc., they are dissatisfied with a comparison that does not include a valuation of their consumption principles and which eventually obliges them to search for themselves behind each proposed offer to position it and to be able to take the right decision [44].

\section{B. Deficiencies Affecting the E-merchant}

E-merchants benefit greatly from the services offered by CSEs. Indeed, having their product catalog displayed in these comparators is a way for them to obtain good visibility, qualified traffic, a way to reach potential customers directly during the purchasing phase and to benefit from a good competitive intelligence tool [25]. However, this does not remain without disadvantages, because some e-merchants feel that they are serving as a decoy by inflating the comparator's list of results, giving them credibility in the process, and allowing their competitors to distinguish themselves. Among the shortcomings suffered by e-merchants are those presented in the diagram in Fig. 4.

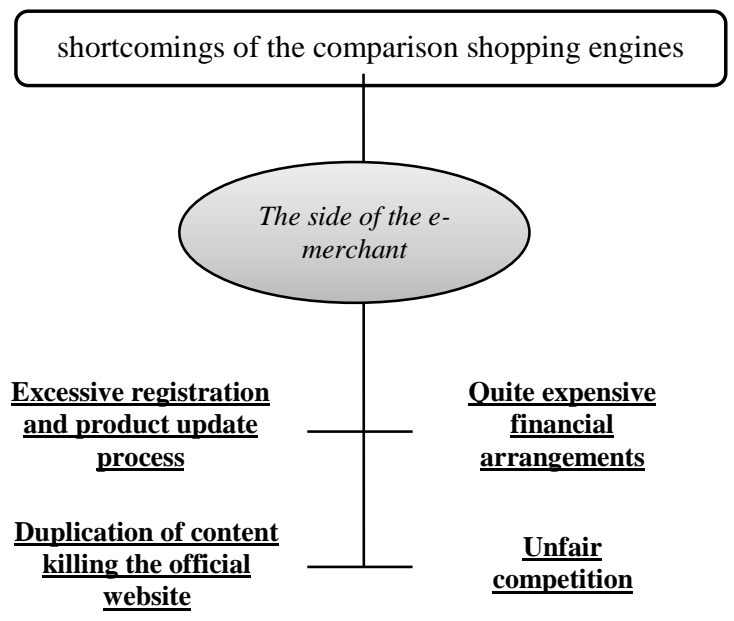

Fig. 4. The Shortcomings of the CSEs: E-merchant End.

1) Quite expensive financial arrangements: It is not easy to be part of the top lists of comparison shopping engines. First, there are often fairly expensive financial arrangements in order to be frequently recommended or well ranked in the list of recommendations [30]. These arrangements can be manifested in different packs as explained earlier: cost-peraction (CPA), cost-per-click (CPC), referencing, registration and handling fees, subscription, etc. [31] which may represent a big burden for e-merchants in startups, unable to invest so much money in communication.

2) Unfair competition: In the case of the majority of CSEs, the e-merchant capable of paying more will be the most recommended[11]. This rule is discouraging to other growing e-merchants because, despite the quality of their offers, they will remain in the shadow of large websites able to pay the price necessary to have the greatest traffic and the best visibility.

3) The overly cumbersome registration \& product update process: When the updating of the products on the CSE is done manually, it requires a lot of investment in terms of effort, time and even money, once delegated to a service provider.

4) Duplication of content can harm official site traffic: The value of an online store lies in the richness of its content. An e-merchant administrator duplicates the content of his official website on the CSE when he puts the products under the same name, description, photo, etc. Thus, depending on how Google works, it will consider that there is no use of displaying all these multiple websites with the same content 
and will choose the one with the greatest traffic that it considers most reliable to place on first pages while the others will be put, including the official website, in the outskirts of the web (relegated to the 10th page or beyond) [45]. Therefore, for the e-merchant to be able to fight against this form of cannibalization, it will be necessary to provide the means to differentiate the content of the official site with each CSEs. This can be costly and time-consuming and must be done by highly skilled people to differentiate the content offered without altering the nature of the offer.

\section{DISCUSSION OF NEW INNOVATIONS AND ASPIRATIONS FOR THE FUTURE}

\section{A. State of the Art on the different Scientific Innovations around the CSES}

In the face of the aforementioned shortcomings of the comparison shopping engines, recognizing the limits of a solution and the causes of its dysfunction is not enough, it is also necessary to seek to improve it or find possible alternatives.

With this in mind, the article discusses some of the work that has been done in this area.

In a 1998 study entitled "Agent-mediated Integrative Negotiation for Retail Electronic Commerce" [46], the challenge was to generate a list of products that were functional and adapted to consumer criteria without being limited to the price factor alone. This work focused on generating customized lists of product and e-merchant information associated with the corresponding specifications (prices, etc.) and incentives (extended warranty, delivery time, etc.). The thing that is currently being done partially in the CSEs. Thus, it was based on multiple attribute utility theory (MAUT)[47], which is founded on two distinct analyses: the first is uncertainty, which covers the consideration of certain uncertainty on the consumer side for situations such as "how much should I trust this merchant?" and on the e-merchant side for others such as "what will be the demand for this product?", thus it addresses the uncertainties of attribute values in purchasing decisions in relation to customers and bid decisions in relation to emerchants. The second analysis is the utility analysis, or in this case, the preference, which analyzed multiple attribute preferences[46]. Inasmuch as these analyses have had acceptable results they have not been able to adapt over time to the satisfaction of the functionality, adaptability, and customization of the products offered at the request of the consumer. To which the approach of this work required direct feedback for the acquisition of uncertainties and utilities before the application of their MAUT theory for the generation of the customized ranked list. This represented a burden for consumers who should be involved in collecting uncertainties [32].

In addition, another research project focused on this vision in 2002. Soe Tyran in her article "A personalized and integrative comparison-shopping engine and its applications" [32] raised the question of considering the existing differences between e-consumers and also those of e-merchants in the comparison of offers while disapproving the comparators limited only to price. In her article she proposes a solution that she called "personalized sales agents and integrators", the latter can be summarized as a comparison engine that includes both a "product / merchant information collector" and a "behaviour extractor" that acquires consumers' behaviour towards products (the time spent by the consumer browsing the details of articles, surfing the online store, the websites that the consumer browses), A "user profile manager" that keeps track of the most common consumer behaviors and behavioral analysis results generated by "the personalized online ranking module" that covers the agent-activated behavioral analysis of interactions (With consumer behavior history and product/merchant information, the module does the necessary reasoning / calculation / analysis of multiple product/merchant terms to provide a better personalized ranking. Where the favorite objects are placed first) [32].

In her work, Soe Tyrant used the interactive power of the Web to analyze user behavior to capture dynamic consumer preferences over time, whereas for ranking, she used learning by reinforcing time differences with the approximation of value. With the aim of finding the list of products / e-merchants classified in order of importance, where the position of the products in the classification is proportional to the interests of the consumer [32].

In another case, in 2010, research again focused on this theme but remained limited, once again, to the price factor. In an article entitled: "A comparison shopping optimization model based on suppliers' pricing contexts" [48], Yong Sik Chang and Kyoung Jun Lee wanted to emphasize the importance of taking into account the supplier's pricing strategy in the comparison. Thus, they proposed a comparative shopping optimization model based on supplier price contexts that offers, to online consumers, suppliers sorted by effective and realistic prices. This is interesting, but not very comprehensive given the vision undertaken by the previous articles. [48].

Just after, in 2011, another research project focused on the shopbots, but from a completely different angle, not covering the comparative assistance of the filters associated with the ecustomer/e-merchant. But rather, globalizing research and allowing access to all the world's products. The article "Designing a cross-language comparison-shopping agent" [49] came with the proposal of a shopbot called "WebShopper" to help customers find and compare e-merchants who market their products using different languages, which can be interesting since the majority of suppliers offer international delivery, this shopbot is built with a multilingual ontology based on a semi-automatic method using formal conceptual analysis and association analysis [49]. It also generates an automatic method for categorizing product data into predefined classes, in order to reduce the workload of administrators. In addition, a semantic search mechanism based on concept similarity is designed to help customers find more desirable products which can prove to be very interesting [49].

Returning to the comparison based exclusively on the price factor. Another article, in 2015, entitled "Improving comparison shopping agents' competence through selective price disclosure" [50], asks questions about the most effective 
way to present the prize in order to attract the Internet user's attention and increase the chance of their consumption. Thus, it proposed a new approach, called "selective price disclosure", based on the removal of certain product prices from the list presented in order to affect the buyer's beliefs as to the possibility of obtaining more attractive prices. In this context, two methods were proposed. According to the article they are adapted to fully rational buyers to decide which of the prices known by the shopbot should be revealed [50].

\section{B. Innovations Implemented by E-commerce Leaders}

Nowadays, the web is becoming more and more a fertile ground for price comparators. From the moment they realized the profits that could be generated from CSEs, either in advertising, in partnership and especially in collecting consumer data, the majority of digital institutions with strong commercial influence on the net have invested in it. Among the most famous shopping comparison engines in the e-commerce field today, we can mention Google Shopping, NextTag, Price Grabber, Shopping.com and Shopzilla, etc. [13] [51].

The majority of these comparison engines use the price criterion as the sole factor for comparing offers [32]. With the exception of Google shopping, which despite its price valuation, tries to introduce other criteria to improve the quality of its services [17].

1) Google shopping: Google Shopping is a tool to promote an e-merchant's products on the Google network and its partners.

In order to start selling on Google Shopping, it is necessary for an e-merchant to communicate the nature of his product catalog available to Google via Merchant Center (GMC), an interface to configure his data flows to Google Shopping servers as shown in Fig. 5, and as previously explained in the CSE operating system [17].

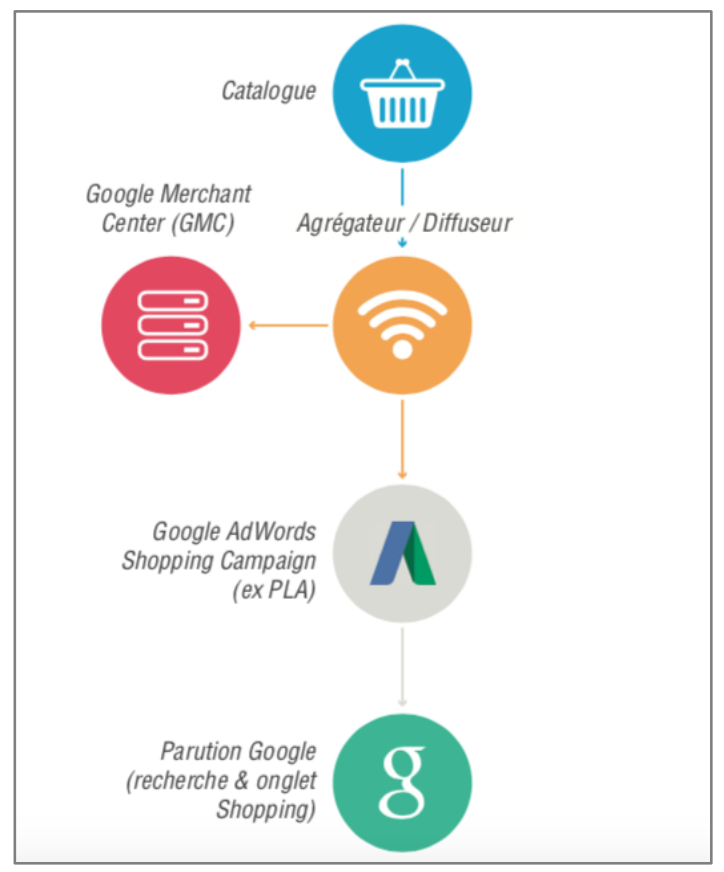

Fig. 5. Google Shopping Operating Process [17].
In turn, Google Shopping feeds comply with certain rules relating to their analysis and verification of offers in order to ensure the quality of the service promised to the consumer, among the rules taken into consideration we find some of them to be related to:

- The legal framework, such as: copyright, counterfeiting law, linguistic, and sexual safety.

- Brand communication (sensitive subject, inciting hatred).

- Transparency (affiliation, misleading representation, bundled offers, etc.).

- To the management of the GMC account, etc. [17].

2) Price Grabber: PriceGrabber.com [52] is a commercial price comparison and distributed content trading website founded in 1999 by former CEO Kamran Pourzanjani and Tamim Mourad[53]. The company works with merchants, retailers, and vendors to provide information on a wide range of products [54].

PriceGrabber is similar in its operation to the majority of CSEs. However, it was the first comparison engine to project information on taxes and shipping costs for a consumer during the price comparison process [13].

\section{ANALYSIS AND DEDUCTIONS}

After a bibliographical study around the comparison shopping engines and the scientific innovations, the research proves that although the offer ranking formula varies from one comparator to another, the comparison of these offers is generally established by considering the price of the products as the major factor.

So, as it can be clear to us that, despite all the transformations in digital marketing and the great centralization on the customer. Scientific research and dominant price comparators [32] [55] have not yet been completely involved and continue to be restricted to the valuation of the price factor without considering all the aspects that are of greater importance to the respect of customer rights and preferences.

\section{CONCLUSION AND OUTLOOK}

Following the problems generated by the excessive overload of the Internet user with online sales offers. The consumer is relieved to turn to comparison shopping engines to save time and energy.

In order to measure consumer satisfaction with this service, this article focused on carrying out an investigation into the comparison shopping engines. The investigation proved interesting in that several shortcomings and limitations were revealed in the quality of the services provided to e-consumers, which is still particularly dissatisfied with the lack of integration of several criteria in addition to the price in the evaluation and comparison of offers.

Thus, despite the growing importance of CSEs for the development of online consumer markets and transactions [25], the leaders of current CSEs and the existing scientific 
innovations have not yet taken into account in the CSE's comparison and evaluation process the consumption characteristics suited to the consumer's personal profile and consumption behavior.

\section{REFERENCES}

[1] K. de Ruyter, D. Isobel Keeling, and L. V. Ngo, "When nothing is what it seems: A digital marketing research agenda," Australas. Mark. J. AMJ, vol. 26, no. 3, pp. 199-203, Aug. 2018.

[2] J. Martins, C. Costa, T. Oliveira, R. Gonçalves, and F. Branco, "How smartphone advertising influences consumers' purchase intention," J. Bus. Res., vol. 94, pp. 378-387, Jan. 2019.

[3] L. Allen and J. L. Zaichkowsky, "Understanding Consumer Confusion On-line $<$ Superscript $>\bullet</$ Superscript $>$," in Assessing the Different Roles of Marketing Theory and Practice in the Jaws of Economic Uncertainty, Springer, Cham, 2015, pp. 39-44.

[4] E. Falque, "Are consumers suffering from analysis paralysis?" [Online]. Available: https://www.bearingpoint.com/en/our-success/thoughtleadership/are-consumers-suffering-from-analysis-paralysis/. [Accessed: 04-Jan-2018].

[5] V. Swaminathan, "The Impact of Recommendation Agents on Consumer Evaluation and Choice: The Moderating Role of Category Risk, Product Complexity, and Consumer Knowledge," J. Consum. Psychol., vol. 13, no. 1/2, pp. 93-101, 2003.

[6] J. O. Kephart and A. R. Greenwald, "Shopbot Economics," in Game Theory and Decision Theory in Agent-Based Systems, S. Parsons, P. Gmytrasiewicz, and M. Wooldridge, Eds. Boston, MA: Springer US, 2002, pp. 119-158.

[7] G. Lipovetsky, Le Bonheur paradoxal. Essai sur la société d'hyperconsommation, Gallimard. 2006.

[8] N. Herpin, Sociologie de la consommation. Paris: La Découverte, 2004.

[9] A. Bétizeau-Morge and A. Basquin, "Chapitre 22 - Psychothérapies comportementales dans les addictions sans substance (jeu pathologique, achats compulsifs)," in Addictologie (3e édition), M. Lejoyeux, Ed. Paris: Content Repository Only!, 2017, pp. 399-407.

[10] A. L. Montgomery, K. Hosanagar, R. Krishnan, and K. B. Clay, "Designing a Better Shopbot," Manag. Sci., vol. 50, no. 2, pp. 189-206, 2004.

[11] A. R. Greenwald and J. O. Kephart, "Shopbots and Pricebots," in Agent Mediated Electronic Commerce II, 2000, pp. 1-23.

[12] "Shopping Engine History - SingleFeed, Shopping Engines made easy," SINGLE FEED. [Online]. Available: https://www.singlefeed.c om/resources/enginehistory.php. [Accessed: 04-Jan-2018].

[13] W. Yun, Comparison-Shopping Services and Agent Designs. IGI Global, 2009.

[14] "The rise of price comparison sites in South East Asia," Insurance Post, 18-Dec-2013. [Online]. Available: https://www.postonline.co.uk/node/ 2319717. [Accessed: 05-Jan-2018].

[15] "Les fiches pratiques TIC - CCIT des Alpes de Haute-Provence." [Online]. Available: http://www.digne.cci.fr/fiches-pratiquestic,555.html. [Accessed: 05-Jan-2018].

[16] K. Shah, B. Mulhern, L. Longworth, and M. F. (Bas) Janssen, "An Empirical Study of Two Alternative Comparators for Use in Time Trade-Off Studies," Value Health, vol. 19, no. 1, pp. 53-59, Jan. 2016.

[17] M. Largeron and Lengow, "MAÎTRISEZ LES CAMPAGNES GOOGLE SHOPPING POUR AUGMENTER VOS VENTES !" Livre Blanc Google Shopping.

[18] R. Garfinkel, R. Gopal, B. Pathak, and F. Yin, "Shopbot 2.0: Integrating recommendations and promotions with comparison shopping," Decis. Support Syst., vol. 46, no. 1, pp. 61-69, Dec. 2008.

[19] "Data Feed Management and Data Feed Optimization Services by SingleFeed - Comparison Engines Made Easy." [Online]. Available: https://www.singlefeed.com/. [Accessed: 06-Jun-2019].

[20] "FeedPerfect: Comparison Shopping Engine Solution." [Online]. Available: https://www.feedperfect.com/. [Accessed: 06-Jun-2019].
[21] B. C. Brown, The Complete Guide to Affiliate Marketing on the Web: How to Use and Profit from Affiliate Marketing Programs. Atlantic Publishing Company, 2009.

[22] R. Guttman, A. Moukas, and P. Maes, "Agents as Mediators in Electronic Commerce," in Intelligent Information Agents: Agent-Based Information Discovery and Management on the Internet, M. Klusch, Ed. Berlin, Heidelberg: Springer Berlin Heidelberg, 1999, pp. 131-152.

[23] A. Parasuraman, V. A. Zeithaml, and L. L. Berry, "SERVQUAL: A multiple-item scale for measuring consumer perceptions of service quality," J. Retail., vol. 64, no. 1, pp. 12-40, 1988.

[24] V. A. Zeithaml, A. Parasuraman, and A. Malhotra, "Service quality delivery through web sites: A critical review of extant knowledge," J. Acad. Mark. Sci., vol. 30, no. 4, p. 362, Sep. 2002.

[25] M. D. Smith, "The impact of shopbots on electronic markets," J. Acad. Mark. Sci., vol. 30, no. 4, p. 446, Sep. 2002.

[26] D. Ronayne, "Price Comparison Websites," University of Warwick, Department of Economics, 1056, 2015.

[27] R. A. Nelson, R. Cohen, and F. R. Rasmussen, "An Analysis of Pricing Strategy and Price Dispersion on the Internet," East. Econ. J., vol. 33, no. 1, pp. 95-110, 2007.

[28] M. D. Smith and E. Brynjolfsson, "Consumer Decision-Making at an Internet Shopbot: Brand Still Matters," J. Ind. Econ., vol. 49, no. 4, pp. 541-558, 2001.

[29] "Le marketing digital ses formes et ses enjeux - E-book - Livres pour tous | Livres gratuits." [Online]. Available: http://www.livrespourtous .com/e-books/detail/Le-marketing-digital-ses-formes-et-sesenjeux/onecat/Livres-electroniques+Documents-etessais+Articles/0/all_items.html. [Accessed: 05-Jun-2019].

[30] N. Vulkan, The Economics of E-commerce: A Strategic Guide to Understanding and Designing the Online Marketplace. Princeton University Press, 2003.

[31] "Ifop - Les internautes et les comparateurs de prix," ifop.com, Avril2011. [Online]. Available: http://www.ifop.com/?option=com publication\&type $=$ poll\&id=1463. [Accessed: 04-Jan-2018].

[32] S.-T. Yuan, "A personalized and integrative comparison-shopping engine and its applications," Decis. Support Syst., vol. 34, no. 2, pp. 139-156, Jan. 2003.

[33] G. Kanny, D. Dano, J.-L. Danan, C. Astier, and S. Lefevre, "Information des consommateurs allergiques et étiquetage : actualités," Rev. Fr. Allergol., vol. 55, no. 7, pp. 483-491, Nov. 2015.

[34] W. Yanhui and N. H. E. Aoud, "Le besoin de réassurance : de la psychologie au comportement du consommateur Une investigation théorique appliquée au cas de la consommation alimentaire moderne," Rev. Gest. Organ., vol. 7, no. 1, pp. 1-8, Mar. 2015.

[35] M. Boisset, "Les «Métaux Lourds» dans l'alimentation: quels risques pour les consommateurs ?," Médecine Mal. Métaboliques, vol. 11, no. 4, pp. 337-340, Jun. 2017.

[36] F. Marano and R. Guadagnini, "Les nanoparticules dans l'alimentation : quels risques pour le consommateur ?," Cah. Nutr. Diététique, vol. 48, no. 3, pp. 142-150, Jun. 2013.

[37] C. Julia et al., "Impact d'un système d'information nutritionnel simplifié sur les achats des consommateurs," Nutr. Clin. Métabolisme, vol. 31, no. 3, p. 228, Sep. 2017.

[38] "INCI Beauty * Analysez la composition de vos cosmétiques." [Online]. Available: https://incibeauty.com/. [Accessed: 06-Jun-2019].

[39] "Appli QuelCosmetic - Une application mobile gratuite pour choisir ses." [Online]. Available: https://www.quechoisir.org/applicationmobile-quelcosmetic-n52804/. [Accessed: 06-Jun-2019].

[40] Y. Tamura, "Migrant smuggling," J. Public Econ., vol. 94, no. 7, pp. 540-548, Aug. 2010.

[41] F. Marticotte and M. Arcand, "Schadenfreude, attitude and the purchase intentions of a counterfeit luxury brand," J. Bus. Res., vol. 77, pp. 175183, Aug. 2017.

[42] L. Casola, S. Kemp, and A. Mackenzie, "Consumer decisions in the black market for stolen or counterfeit goods," J. Econ. Psychol., vol. 30, no. 2, pp. 162-171, Apr. 2009. 
[43] J. H. Antil, "Socially Responsible Consumers: Profile and Implications for Public Policy," J. Macromarketing, vol. 4, no. 2, pp. 18-39, Dec. 1984.

[44] A.-S. Binninger and I. Robert, "Consommation et développement durable, Consumption and sustainable development: toward a segmentation based on sensitivity and behavior, Consumo y desarrollo sostenible : hacia una segmentación de las sensibilidades y de los comportamientos," Rev. Sci. Gest., no. 229, pp. 51-59, 2008.

[45] N. ALTRUP, "The Danger of Duplicate Content - 417 Marketing World-Class SEO,” 417 Marketing, 04-Feb-2019. [Online]. Available: https://www.417marketing.com/the-danger-of-duplicate-content/. [Accessed: 18-Jun-2019].

[46] R. H. Guttman and P. Maes, "Agent-Mediated Integrative Negotiation for Retail Electronic Commerce," in Agent Mediated Electronic Commerce, 1998, pp. 70-90.

[47] J. S. Dyer, "Maut-Multiattribute Utility Theory," in Multiple Criteria Decision Analysis: State of the Art Surveys, Springer, New York, NY, 2005, pp. 265-292.

[48] Y. S. Chang and K. J. Lee, "A comparison shopping optimization model based on suppliers' pricing contexts," Expert Syst. Appl., vol. 37, no. 8, pp. 5736-5744, Aug. 2010.

[49] S.-L. Huang and Y.-H. Tsai, "Designing a cross-language comparisonshopping agent," Decis. Support Syst., vol. 50, no. 2, pp. 428-438, Jan. 2011.
[50] C. Hajaj, N. Hazon, and D. Sarne, "Improving comparison shopping agents' competence through selective price disclosure," Electron. Commer. Res. Appl., vol. 14, no. 6, pp. 563-581, Oct. 2015.

[51] E. Turban, J. Outland, D. King, J. K. Lee, T.-P. Liang, and D. C. Turban, "Retailing in Electronic Commerce: Products and Services," in Electronic Commerce 2018: A Managerial and Social Networks Perspective, E. Turban, J. Outland, D. King, J. K. Lee, T.-P. Liang, and D. C. Turban, Eds. Cham: Springer International Publishing, 2018, pp. 79-122.

[52] "Check online store ratings and save money with deals at PriceGrabber.com.” [Online]. Available: http://www.pricegrabber.com/. [Accessed: 18-Jun-2019].

[53] C. Sherman, Google Power. McGraw Hill Professional, 2005.

[54] K.-P. Mehdi, Consumer Behavior, Organizational Development, and Electronic Commerce: Emerging Issues for Advancing Modern Socioeconomies: Emerging Issues for Advancing Modern Socioeconomies. IGI Global, 2008.

[55] M. HAYES, "10 Best Comparison Shopping Engines to Increase Ecommerce Sales - Shopify," Shopify's Ecommerce Blog - Ecommerce News, Online Store Tips \& More. [Online]. Available: https://www.shopify.com/blog/7068398-10-best-comparison-shoppingengines-to-increase-ecommerce-sales. [Accessed: 04-Jan-2018]. 